\title{
Evaluation of wheelchair tire rolling resistance using dynamometer- based coast-down tests
}

\author{
Andrew M. Kwarciak, MS; ${ }^{1}$ Mathew Yarossi, BS; ${ }^{*}$ Arvind Ramanujam, MS; ${ }^{1}$ Trevor A. Dyson-Hudson, MD; ${ }^{1-2}$ \\ Sue Ann Sisto, PT, PhD ${ }^{1-3}$ \\ ${ }^{1}$ Kessler Foundation Research Center, West Orange, $N J ;{ }^{2}$ Department of Physical Medicine and Rehabilitation, Uni- \\ versity of Medicine and Dentistry of New Jersey, New Jersey Medical School, Newark, NJ; ${ }^{3}$ Division of Rehabilitation \\ Sciences, Stony Brook University, Stony Brook, NY
}

\begin{abstract}
The objective of this study was to compare the rolling resistance of four common manual wheelchair tires (two pneumatic and two airless solid) and the solid tires used on a commercially available force- and moment-sensing wheel. Coast-down tests were performed with a wheelchair positioned on a two-drum dynamometer. Within each of three load conditions, tire type had a significant effect on rolling resistance $(p<$ $0.001)$. The pneumatic tires had smaller rolling resistances and were less affected by load increases than the solid tires. Within the two tire types, higher air pressure or firm ness and lower profile tread corresponded to less rolling resistance. Wheelchair users, clinicians, and researchers must consider the effect of tire type on wheelchair rolling resistance when selecting a manual wheelchair tire.
\end{abstract}

Key words: coast-down test, dynamometer, inflation pressure, manual wheelchair, pneumatic tire, rehabilitation, rolling resistance, solid tire, tire type, wheeled mobility.

\section{INTRODUCTION}

Selection and maintenance of wheelchair tires is crucial to helping manual wheelc hair users maximize their wheeling efficiency. One of the most important factors to consider when selecting a tire is its rolling resistance. Rolling resistance is the forc e opposing the motion of a tire as it rolls across a surface. The main cause of rolling resistance is inelastic deformation of the materials com- prising the tire and/or the su rface [1]. The amount of deformation is determined primarily by tire design, material composition, laden weight, and surface interactions such that, for a given surface, decreasing the hardness (or inflation pressure) of a tire and/or increasing its laden weight will increase deformation and thus increase rolling resistance [1-3].

Kauzlarich and Thacker presented a set of equations to determine the rolling resistance of a wheelchair tire using a ma terial-based analysis [1]. Other studies have determined rolling resistance experimentally using treadmill drag tests [3-5] or coast-down tests [6-7]. Throughout these experiments, pneumatic wheelchair tires have exhibited lower rolling resistances than solid airless tires. Even at 50 perc ent of their recommended inflation pressure, pneumatic tires have been shown to roll farther than solid tires [6].

Despite the advantages of pneumatic tires, including improved ride comfort [5], solid tires are still used by many manual wheelchair users. Solid tires require relatively no

\footnotetext{
Abbreviations: $\mathrm{CDD}=$ coast-do wn distance, MANOV A = multivariate analysis of variance, $\mathrm{SD}=$ standard deviation.

* Address all corr espondence to Mathew Yarossi, BS; Kessler Foundation Research Center, 1199 Pleasant Valley Way, West Orange, NJ 07052.

Email: myarossi@kesslerfoundation.org

DOI:10.1682/JRRD.2008.10.0137
} 
maintenance, short of replacement, and have no risk of puncture or becoming flat. For these reasons, solid tires are also commonly used on instrumented wheelchair wheels that measure the forc es and moments applied to the pushrim during manual wheelchair propulsion [810]. One example is the Sma rtWheel ${ }^{\circledR}$ (Three Rivers Holdings, LLC; Mesa, Arizona), a commercia lly available force- and moment-sensing wheel that comes standard with a full-profile solid tire (Alshin $\mathrm{T}$ ire Corporation; Rancho Cucamonga, California). The SmartWheel has been used in multiple research studies [10-12] and is becoming more popular as a clinical tool for objectively evaluating manual wheelchair propulsion [13]. Despite the benefits of th e SmartWheel and other instrumented wheelchair wheels, the us e of solid tires may affect their ability to obtain representative measurements of wheelchair propulsion. Compa red with pneumatic tires, solid tires a re less efficient; thus, measurements obtained from instrumented wheels equipped with solid tires may be skewed toward less efficient propulsion. The relative im pact of solid tires is not fully known since previous studies have not te sted the types of solid tires used on instrumented wheels nor have they tested a variety of commonly used tires under multiple load conditions [5-6].

Given the limited informat ion on the rolling resis tance of wheelchair tires, additional investigation is needed. Therefore, the purpose of this study was to determine the rolling resistance of four commonly us ed manual wheelchair tires and the Alshin tire used on the SmartWheel through dynamometer-based coast-down tests. Unlike previous coast-dow $\mathrm{n}$ tests that were performed overground [6-7], coast-down tests for this study were performed on a two-drum dynamometer, described elsewhere [14]. Dynamometer-based testing has been used in studies of manual wheelchair propulsion [9,15-17] and offers an advantageous environment for coast-down tests.
With the wheelchair fixed to a platform and only the rear wheels resting on the drum $\mathrm{s}$, the dynamometer setup eliminates the ef fects of caster rolling resistance and aerodynamic drag and provides a consistent test of rear tire rolling resistance. Based on the results of previous studies [5-6], we hy pothesized that the pn eumatic tires would have significantly lower rolling resistance than the solid airless tires.

\section{METHODS}

Five different sets of tires were tested: (1) Primo VTrak pneumatic tires (Gallop Cycle Corp; Long Beach, California), (2) Pri mo Orion pneumatic tires, (3) KIK Mako solid tires (Amerityre Cor p; Boulder Ci ty, Nevada), (4) Cheng Shin pneumatic tires (Cheng Shin Rubber Ind Co, Ltd; Xiamen, China) with solid inserts, and (5) Alshin solid tires. Each set of tires was mounted on a pair of $0.61 \mathrm{~m}$ Sunrims SW600 wheels with radial spokes (Hayes Bicycle Group; Mequon, W isconsin). All pneumatic tires were inflate $d$ to the manufacturer 's recommended pressure. Table 1 lists the relevant characteristics and recommended pressure of ea ch tire. The calculation of tire moment of inertia is described in the Appendix (available online only).

Each set of wheels was pla ced on a Quickie GPV rigid-frame wheelchair (Sunrise Medical; Longmont, Colorado; weight: $9 \mathrm{~kg}$, width: $0.46 \mathrm{~m}$, re ar wheel camber: $3.5^{\circ}$ ). The wheelc hair was secured over a two-drum dynamometer such that the rear wheels rested on separate drums, allowing for independent wheel rotation (Figure 1). A custom mount was fixed to the seat of the wheelchair, and barbell plates $(45.4 \mathrm{~kg}, 68.0 \mathrm{~kg}$, and $90.7 \mathrm{~kg})$ were added to the mount to create three weight conditions. A calibrated force plate (Ber tec Corp; Col umbus, Ohio) was used to determine the load supporte $d$ by each rear

Table 1.

Tire characteristics.

\begin{tabular}{llcccc}
\hline \multicolumn{1}{c}{ Tire } & Type & Profile $^{*}$ & Mass $^{\dagger}$ (kg) & Diameter (cm) $^{\text {Moment of Inertia }^{\dagger}}$ \\
\hline Primo V-Trak & Pneumatic & Low & 0.36 & 59.6 & 0.025 \\
Primo Orion & Pneumatic & Full & 0.64 & 0.5 & 0.045 \\
KIK Mako & Solid & Low & 0.48 & 58.8 & 0.034 \\
Cheng Shin & Solid Insert & Full & 1.16 & 60.9 & 0.081 \\
Alshin & Solid & Full & 0.71 & 60.1 & 0.050 \\
\hline
\end{tabular}

${ }^{*}$ Low refers to tread type C-1025 or similar; full refers to tread type C-63 or similar.

$\dagger$ Includes mass of tire and tube or solid insert (if applicable). 


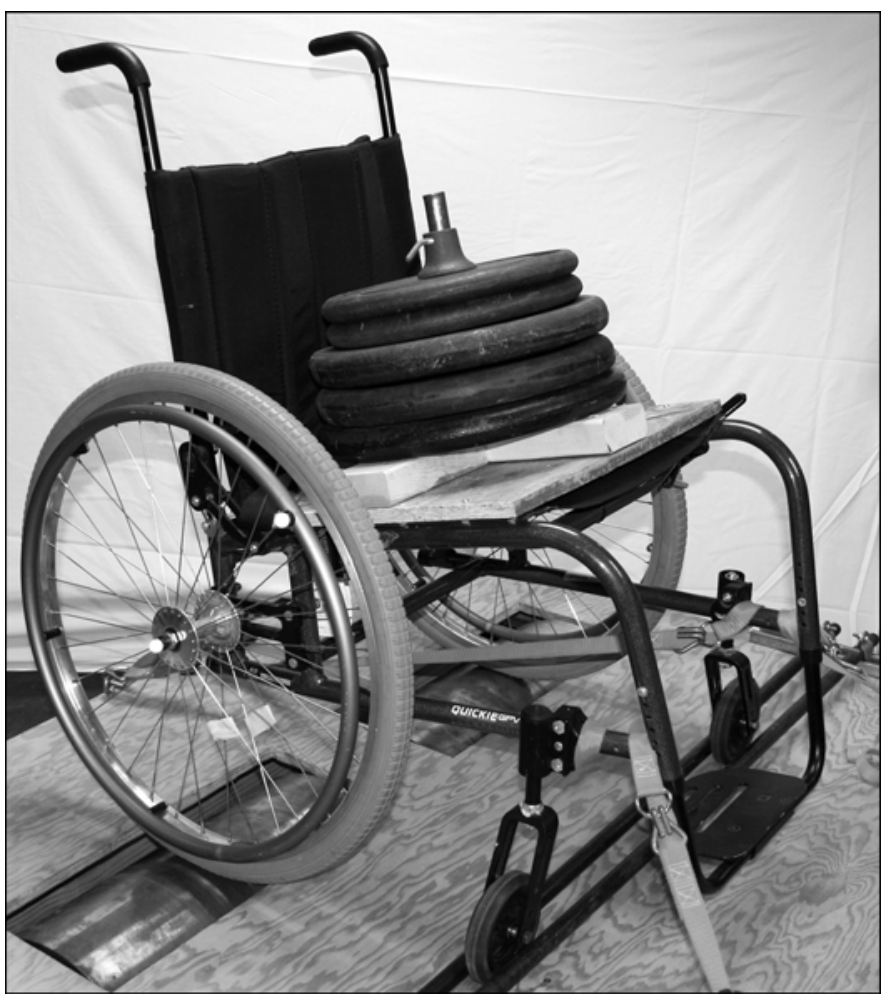

Figure 1.

Test setup for solid-insert Cheng Shin tires and 377.6 N load condition.

wheel under ea ch condition. To minimize wheelchair vibration and shifting on the dynamometer, we only used the right wheel for testing. Thus, the average load supported by the right wheel under each weight condition was $223.6 \mathrm{~N}, 291.3 \mathrm{~N}$, and $377.6 \mathrm{~N}$, respectively. These loads include the weight of the wheelchair, wheel, test mount, and barbell plates.

The right wheel was manually spun to a tangential velocity of at least $2.0 \mathrm{~m} / \mathrm{s}$. Velocity was measured with an encoder fitted to the surface of the dynamometer drum and an oscilloscope (Agilent Technologies, Inc; Santa Clara, California). Once the s peed was reached, rotational force was discontinued and the wheel was allowed to coast down to a complete stop. Ten trials were performed for each tire under each load (150 trials total). Spherical reflective markers were placed on the hub and pushrim of the right wheel. During each trial, the move ments of the markers were recorded at $120 \mathrm{~Hz}$ with a Vicon motion capture system (Vicon; Oxford, United Kingdom).

\section{DATA ANALYSIS}

In order to calculate the rolling resistance of each tire from dynamometer-based coast-down tests, we needed to determine the deceleration of the wheel. Markers on the hub $\left(\mathrm{Hub}_{\mathrm{xyz}}\right)$ and pushrim $\left(\operatorname{Rim}_{\mathrm{xyz}}\right)$ were used to calculate wheel deceleration in each trial. These data were chosen over measurements made by the encoder (at a rate of $30 \mathrm{~Hz}$ ) because the Vicon system provided a higher collection rate. Marker data were filtered with a secondorder, zero-phase, low-pass Butterworth filter with a $6 \mathrm{~Hz}$ cutoff frequency [18]. The rotation of the wheel between each time point $(q)$ was then determined from the law of cosines:

$$
\theta=\cos ^{-1}\left(\frac{A \times B}{\|A\|\|B\|}\right),
$$

where $A=\operatorname{Rim}_{\mathrm{xyz}}(i)-\operatorname{Hub}_{\mathrm{xyz}}(i)$ and $B=\operatorname{Rim}_{\mathrm{xyz}}(i+1)-$ $\mathrm{Hub}_{\mathrm{xyz}}(i+1)$. The rate of wheel rotation, or angular velocity, was calculated by dividing the change in angle by the change in time for each frame. To account for differences in wheel size, we converted angular velocity to linear velocity by multiplying angular velocity by wheel radius. All trials were required to include the same range of linear velocities; therefore, data were trimmed to those points that corresponded to linear velocities between 1 and $2 \mathrm{~m} / \mathrm{s}$. A line was fit to the linear velocity $(v)$ data to determine the deceleration of the wheel $\left(a_{d}\right)$ :

$$
v=a_{d} t+v_{0},
$$

where $t$ is the time to coast down from $2 \mathrm{~m} / \mathrm{s}$ to $1 \mathrm{~m} / \mathrm{s}$ and $v_{0}$ is the initi al velocity of the wheel $(1.99 \pm 0.01 \mathrm{~m} / \mathrm{s})$. Goodness-of-fit was determined by calculating the coef ficient of determination $\left(R^{2}\right)$ for each linear regression. Overall, the linear regressions accurately represented the data (mean $R^{2}=0.998$, range: $0.960-0.999$ ).

The calculation of rolling resistance was based upon a model of wheelchair propulsion on an inertial roller system presented by Cooper [19]. To simplify the model, we assumed aerodynamic drag, wheel and roller bearing resistances, and variable external resistances were negligible. The resulting equation of rear wheel motion is

$$
T_{w}=\left(I_{r} \frac{R}{r}+I_{w}\right) \alpha_{w}+F_{\mathrm{RR}} R,
$$


where $T_{w}=$ the torque applied by the hand to the rear wheel; $I_{r}$ and $I_{w}=$ the moment of inertia of the roller and the rear wheel, respectively; $r$ and $R=$ the radius of the roller and the re ar wheel, respectively; $a_{w}=$ the angular acceleration of the rear wheel; and $F_{\mathrm{RR}}=$ the rolling resistance force.

Since the equation is being used to describe the rotation of the rear wheel once propulsive force has been discontinued, $T_{w}$ is equal to zero and $a_{w}$ represents the angular deceleration of the wheel. The moments of inertia of the roller $\left(0.87 \pm 0.15 \mathrm{~kg}-\mathrm{m}^{2}\right)$ and the wheels $(0.12 \pm$ $0.02 \mathrm{~kg}-\mathrm{m}^{2}$ ) were determined experimentally using the acceleration method described by DiGiovine et al. [20]. A detailed description of the experimental calculations is provided in the Appendix (available online only). By substituting the values of $I_{r}$ and $r(0.16 \mathrm{~m})$ into Equation 3 and rewriting $a_{w}$ as linear deceleration divided by radius $\left(a_{d} / R\right)$, we calculated rolling resistance force from the wheel radius, inertia, and deceleration:

$$
F_{\mathrm{RR}}=\frac{-a_{d}}{R^{2}}\left(I_{w}+5.47 R\right) .
$$

The rolling re sistance of each tire under e ach load was represented by the mean $F_{R R}$ of all 10 trials \pm 1 standard deviation (SD). A pair of one-way analyses of variance were performed to compare the rolling resistances across tire type (pneumatic and solid) and tire profile (low and full) within each load, ass uming independence between coast-down trials within each tire. A repeate d measures multivariate analysis of va riance (MANOVA) was per formed to compare the effect of load on rolling resistance. Statistical analyses were performed using SPSS software (SPSS Inc; Chicago, Illinois) with significance set to $p<0.05$.

In order to compare our results with those of Sawatzky et al. [6], we also made calculations of coastdown distance (CDD). C DD was computed using the equation of motion in which acceleration is a ssumed to be constant:

$$
\mathrm{CDD}=\frac{1}{2} a_{d} t^{2}+v_{0} t
$$

where $t$ is the time to coast down to a complete stop; therefore, CDD represents the entire coast-down of the wheel (for better comparison of results) and not just the 1 to $2 \mathrm{~m} / \mathrm{s}$ range over which the calculation of $F_{R R}$ was based. Coast-down time was calculated from Equation 2 by setting velocity equal to zero and substituting the values of $a_{d}$ and $v_{0}$. All calculations were performed using custom programs developed in MATLAB (The MathWorks, Inc; Natick, Massachusetts), and all data are presented as mean $\pm \mathrm{SD}$.

\section{RESULTS}

Figure 2 shows the mean rolling resistance force for all five tires as computed from Equation 4. Given the small SD $(0.13 \mathrm{~N})$ within each set of trials, no error bars were included. Under each load, the pneumatic tires had significantly less rolling resistance than the solid airless tires $(p<0.001)$ and the low-profile ti res had signifi cantly less rolling resistance than the full-profile tires $(p £$ 0.006). Pairwise comparisons within the MANOVA revealed significant dif ferences in rolling resistance between all tires across all loads $(\quad p<0.001)$. The MANOVA also revealed a significant interaction between rolling resistance and load $(p<0.001)$, confirming the distinct effect of each load condition.

To determine the relative differences between the tires, we performed indivi dual comparisons within tire type (pneumatic and solid) and tire profile (low and full). Between the pneumatic tires, the mean rolling resistance of the Primo Orion was $11.0 \pm 1.3$ percent greater than the Primo V-Trak. Between the solid tires, the mean rolling resistance of the Alshin was $36 \pm 10$ percent greater than

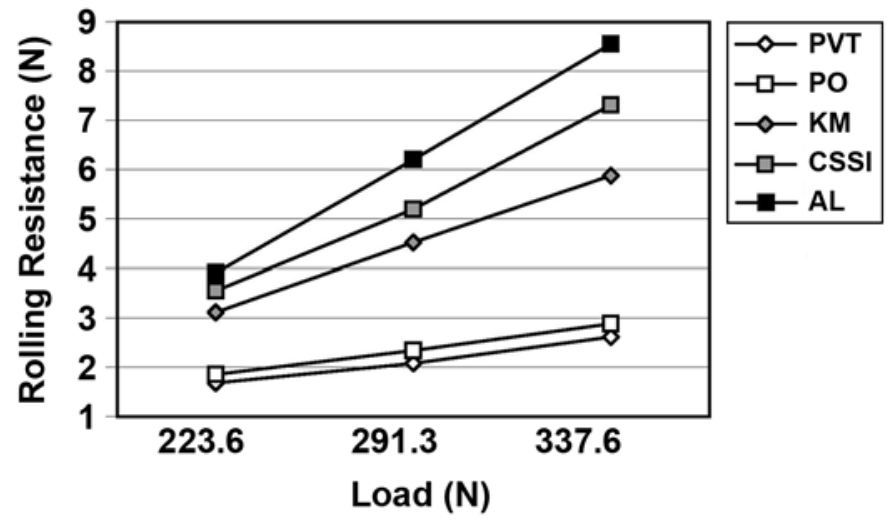

Figure 2.

Mean coast-down deceleration for each tire under each load. $\mathrm{AL}=$ Alshin, CSSI $=$ Cheng Shin with solid insert, $\mathrm{KM}=\mathrm{KIK}$ Mako, $\mathrm{PO}=$ Primo Orion, PVT $=$ Primo V-Trak. Diamond markers indicate lowprofile tires and square markers indicate full-profile tires. 
the KIK Mako and $15.0 \pm 4.8$ percent greater th an the solid-insert Cheng Shin. On average, the rolling resistance of the solid-insert Cheng Shin tire was $18.0 \pm 5.7$ percent greater than the KIK Mako. Within profile, the mean rolling resistance of the low-profile solid KIK Mako tire was $109 \pm 21$ percent greater than the low-profile pneumatic Primo V-Trak. For the full-profile tires, both the solidinsert Cheng Shin and solid Alshin tires had rolling resistances that were at least 91 percent greater than the pneumatic Primo Orion tire. The mean rolling resistances of the Cheng Shin and Alshin tir es were $122 \pm 31$ percent and $157 \pm 44$ percent greater than the Primo Orion tire, respectively.

Across the three loads, the pneumatic tires were more resistant to the effect of load, exhibiting a more moderate change (lesser slope) in rolling resistance. The average increase in rolling resistance for both pneumatic tires was $25 \pm 1.4$ percent. On the other hand, the solid tires were more prone to the loa $\mathrm{d}$ effect and exhibited larger, more variable increases in rolling resistance. Between the 223.6 N and 291.3 N loads, rolling resista nce increased 45 percent for the solid KIK Mako tire, 46 percent for the solid-insert Cheng Shin tire, and 59 percent for the solid Alshin tire. Between the $291.3 \mathrm{~N}$ and $377.6 \mathrm{~N}$ loads, rolling resistance increased 30 percent for the solid KIK Mako tire, 41 percent for the solid-insert Cheng Shin tire, and 38 percent for the solid Alshin tire. With the exception of the pneumati c Primo V-Trak tire, all tires exhibited smaller percent changes in rolling resistance between the two higher loads.

CDDs were provided as alternative measures of tire performance during coast-down testing. Table 2 lists the mean CDD and percent difference in CDD with respect to the Primo V-Trak tire. Across the $t$ hree loads, the pneumatic tires rolled farther than the solid tires, with the
Primo V-Trak tire posting the longest CDD and the Alshin tire posting the shortest CDD. As load increa sed, the percent difference between the two pneumatic tires was consistent $(12.0 \pm 1.2 \%)$, while the difference between the solid tires and the Primo V-Trak increased from $51.0 \pm 5.8$ to $62.0 \pm 7.4$ percent.

\section{DISCUSSION}

As expected, tire type had a sig nificant effect on wheelchair tire coast-down. Consistent with previously published findings [5-6], the pneumatic tires exhibited less rolling resista nce and had longer CD Ds than the solid tires. Between the two pneumatic tires, the Primo VTrak tire had the smallest rolling resistance and the longest CDD. This is likely because of its higher tire pressure (100 psi vs 75 psi in the Primo Orion) and low, smooth tread (Figure 3). The advantage of these tire characteristics was also seen in the solid tire data. The KIK Mako, the hardest solid tire and the only low-profile model, had the smallest rolling resistance and longest CDD of the three solid tires. Although ti re hardness (or durometer ) was not measured, based on manual pressure, the KIK Mako was assumed to have the highest solid tire durometer, followed by the Cheng Sh in tire with the solid i nsert and the Alshin tire. In terms of rolling ef ficiency, this makes the KIK Mako preferable to the ot her two solid tires; however, the rolling resistance of the KIK Mako was at least 1.68 times greater than the 75 psi pneumatic Primo Orion tire and at least 1.86 times greater than the 100 psi pneumatic Primo V-Trak tire.

Across the thre e loads, the solid tires experienced larger increases in rolling resistance than the pneumatic tires. This is consistent with the results of a study involving

Table 2.

Calculations of mean \pm standard deviation coast-down distance (CDD).

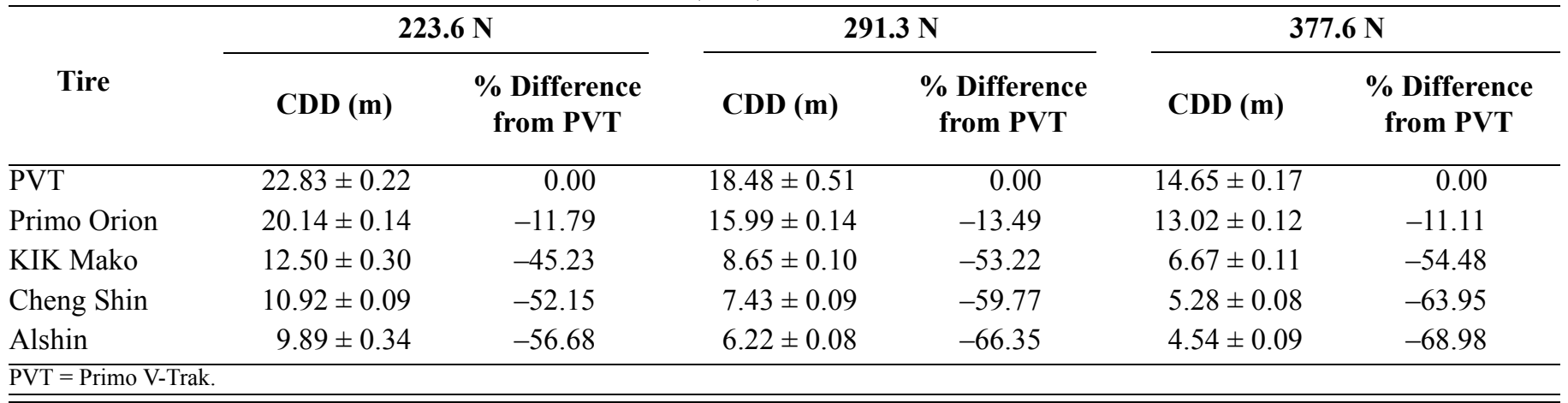




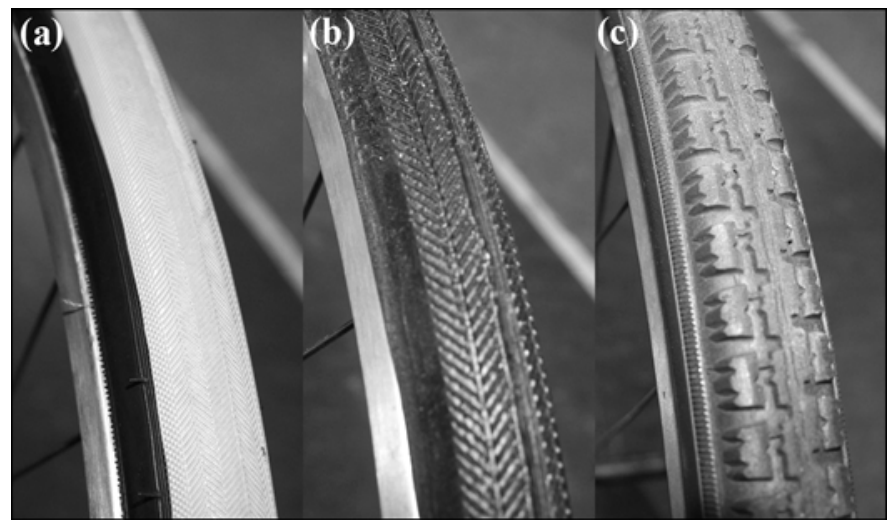

Figure 3.

Tire profiles for (a) Primo V-Trak, (b) KIK Mako, and (c) Primo Orion, Cheng Shin, and Alshin tires (all similar).

treadmill drag testing of several wheelchair tires [5]. In the study, Gordon et al. found that two different polyurethane foam solid tires and a molded polyisoprene solid tire exhibited larger increases in rolling resistance with increased load (ranging from $189 \mathrm{~N}$ to $456 \mathrm{~N}$ per tire) than a 60 psi pneumatic tire [5]. While our data followed similar trends, the actual values of $t$ ire rolling resistance varied. Compared with the results from the $1.33 \mathrm{~m} / \mathrm{s}$ condition [5], the rolling resistance of the 75 psi Primo Orion tire was 20 to 30 percent lo wer (across similar load conditions) than the rolling resi stance of the 60 psi pneu matic tire. Also, the rolling resistance of the solid Alshin tire was 56 to 72 percent lower than the rolling resistance of the circular polyurethane foam tire. These differences in rolling resistance are likely due to differences in specific tire characteristics (i.e., durometer) and/or the influence of the $t$ esting device (dynamometer vs treadmill). Despite the discrepancies, both studies demonstrate the relationship between laden weight, tire type, and rolling resistance. It is important for clinicians and manual wheelchair users to consider that body weight and tire selection both have a significant effect on ease of propulsion. For a heavier individual, the choice of a solid tire over a pneumat ic tire will exacerbate the rolling resistance of the wheelchair. This may lead to higher joint forces during propulsion and a greater risk of sho ulder injury [21]. For such indivi duals, a pneumatic tire, or a firm solid tire like the KIK Mako, would be preferable.

With respect to percent differences in CDDs (Table 3), our results are $\mathrm{c}$ omparable to those obta ined from an overground study performed by Sawatzky et al. [6]. Under an estimated rear wheel load of $208.7 \mathrm{~N}(417.4 \mathrm{~N}$ for the rea $\mathrm{r}$ wheels), they found that a $\mathrm{w}$ heelchair equipped with 65 psi Cheng Shin tires and KIK Mako tires rolled 12 and 51 percent less, respectively, than a wheelchair equipped with 100 psi Primo V-Trak tires. In our study, under a rear wheel load of $223.6 \mathrm{~N}$, the $75 \mathrm{psi}$ Primo Orion tire and the KIK Mako tire rolled 12 and 45 percent less, respectively, than the P rimo V-Trak tire. Both studies demonstrate the ability of the Primo V-Trak tire to roll farther than a lower pressure pneumatic tire or a solid KIK Mako tire for a given coast-down condition. The main difference is that the study conduc ted by Sawatzky et al. [6] was performed overground; therefore, the data repr esent the rolling resistance of the entire wheelchair, which is affected by the rear wheels, caster wheels, and a erodynamic drag [7]. Our study us ed a dynamometer to isolate the re ar wheel and reduce the effects of aerodynamic drag; thus, assuming wheel bearing friction to be negligible, our distances represent the rolling resistance of each tire.

In terms of rese arch applications, solid tires may affect measurements of wh eelchair propulsion biomechanics. For example, the SmartWheel, which uses the

Table 3.

Comparison of coast-down distance (CDD) across studies.

\begin{tabular}{|c|c|c|c|c|}
\hline \multirow{2}{*}{ Tire } & \multicolumn{2}{|c|}{ Current Study (223.6 N) } & \multicolumn{2}{|c|}{ Sawatzky et al. (208.7 N) } \\
\hline & CDD (m) & \% Difference from PVT & CDD (m) & \% Difference from PVT \\
\hline$\overline{\mathrm{PVT}}$ & 22.83 & 0.00 & 10.2 & 0.00 \\
\hline KIK Mako & 12.50 & -45.23 & 5.0 & -50.98 \\
\hline \multicolumn{5}{|c|}{$\begin{array}{l}\text { Sawatzky BJ, Kim WO, Denison I. The ergonomics of different tyres and tyre pressure during wheelchair propulsion. Ergonomics. 2004;47(14):1475-83. } \\
\text { [PMID: 15697064] }\end{array}$} \\
\hline
\end{tabular}


solid Alshin tire, is intended to meas ure the forces and moments applied to the pushrim under normal or nearnormal conditions. However, for in dividuals who normally use pneumatic tires, the Alshin tire presents a relatively high amount of rolling resistance. Compared with that of the full-profile, 75 psi Primo Orion tire, the rolling resistance of the full-profile Alshin ti re was 2.11 to 2.97 times greater under the three loads. Participants may account for this added resistance by increasing pushrim force, lengthening pushrim contact, or incre asing push frequency. Participants may also alter their normal stroke pattern or the $\mathrm{p}$ ath of the hand throughout the stroke [17]. Without knowing how the adaptations in propulsion are made, some desired observations may be obscured. Furthermore, data obtained from wheels with solid tires may lead clinicians and researchers to underestimate the propulsive capability of the individual under evaluation. Individuals who can achieve a functional velocity in a wheelchair with pneumatic tires may not be able to maintain the same level of function with solid tires. In order to obtain the most accurate measure of propulsion, the testing equipment should mimic the participants' nominal setup. Although this is ty pically not possible, efforts should be made to optimize the modifiable components of the equipment, particularly tires, when evaluating manual wheelchair propulsion. Researchers and clini cians should consider using tires that best represent the tires used by their particip ants as well as the potential impact of tire type on manual wheelchair propulsion.

\section{LIMITATIONS}

For convenience, a limite $\mathrm{d}$ number of tires $\mathrm{w}$ ere tested in this study. Inclusion of additional tires may provide more insight into the effects of different pressures, materials, and tire tread designs on rolling resistance. Future studies of whee lchair tires should inc lude additional, newer tires; involve a variety of surfaces and environmental conditions; and explore the effect of tire type and tire maintenance on propulsion biomechanics. In addition, surveys of manual wheelchair users regarding tire selection and satisfactio $\mathrm{n}$ are warranted. This infor mation would provide insight into the factors involving prescription practices and user preferences. Finally, because of the differences in the testing protocols and the tires, direct comparisons to data pres ented in previous studies were not possible, although proportional comparisons revealed similar trends.

\section{CONCLUSIONS}

Pneumatic tires exhibited lower rolling resistance than solid tires in dynamometer-based coast-down tests. Within the two groups, lower profile tread and higher pressure or hardness corresponded to lower rolling resistance. As load increased, solid tires experienced lar ger increases in rolling resistance than pneumatic tires. Given the results of this and previous studies, clinicians and wheelchair users should car efully consider the advan tages and disadvantages associated with each of the different tire types before choosing a manual wheelchair tire. Researchers should also consider the rolling resis tance of solid tires and how their use may effect measurements of wheelchair propulsion.

\section{ACKNOWLEDGMENTS}

\section{Author Contributions:}

Study concept and design: A. M. Kwarciak, M. Yarossi. Acquisition of data: A. M. Kwarciak, M. Yarossi, A. Ramanujam. Analysis and interpretation of data: A. M. Kwarciak, M. Yarossi, A. Ramanujam, T. A. Dyson-Hudson.

Drafting of manuscript: A. M. Kwarciak, M. Yarossi.

Statistical analysis: A. M. Kwarciak, M. Yarossi.

Critical revision of manuscript for important intellectual content:

A. Ramanujam, T. A. Dyson-Hudson, S. A. Sisto.

Obtained funding: S. A. Sisto.

Financial Disclosures: No commercial party having a direct financial interest in the results of the research supporting this article has or will confer a benefit upon the authors or upon any organization with which the authors are associated.

Funding/Support: This material was based on work supported by the New Jersey Commission on Spinal Cord Research (grant 063054 SCR EO) and by the Kessler Foundation.

Additional Contributions: We would like to thank Krupa Savalia, $\mathrm{BS}$, and Jean Lengenfelder, $\mathrm{PhD}$, for their help with the statistical analyses. Andrew M. Kwarciak is now with MAX Mobility, LLC, Antioch, Tennessee; and Sue Ann Sisto is no longer affiliated with the Kessler Foundation.

\section{REFERENCES}

1. Kauzlarich JJ, Thacker JG. Wheelchair tire rolling resis tance and fatigue. J Rehabil Res Dev. 1985;22(3):25-41. 
[PMID: 3835263]

DOI:10.1682/JRRD.1985.07.0025

2. Brubaker CE. Wheelchair prescription: An analysis of factors that af fect mobility and performance. J Rehabil Res Dev. 1986;23(4):19-26. [PMID: 3820118]

3. Lemaire ED, Lamontagne M, Barclay HW, John T, Martel G. A tech nique for the determination of center of gravity and rolling resistance for tilt-seat wheelchairs. J Rehabil Res Dev. 1991;28(3):51-58. [PMID: 1880750]

DOI:10.1682/JRRD.1991.07.0051

4. Van der Woude LH, De Groot G, Hollander AP, Van Ingen Schenau GJ, Rozendal RH. Wheelchair er gonomics and physiological testing of prototypes. Ergonomics. 1986;29(12): 1561-73. [PMID: 3102225]

DOI: $10.1080 / 00140138608967269$

5. Gordon J, Kauzlarich JJ, Thacker JG. Tests of two new polyurethane foam wheelchair tires. J Rehabil Res Dev. 1989; 26(1):33-46. [PMID: 2918486]

6. Sawatzky BJ, Kim WO, Denison I. The ergonomics of different tyres and tyre pressure during wheelchair propulsion. Ergonomics. 2004;47(14):1475-83. [PMID: 15697064] DOI: $10.1080 / 00140130412331290862$

7. Hoffman MD, Millet GY, Hoch AZ, Candau RB. Assessment of wheelchair drag resistance using a coasting deceleration technique. Am J Phys Med Rehabil. 2003;82(11): 880-92. [PMID: 14566157]

DOI:10.1097/01.PHM.0000091980.91666.58

8. Mulroy SJ, Newsam CJ, Gutierrez DD, Requejo P, Gronley JK, Haubert LL, Perry J. Effect of fore-aft seat position on shoulder demands during wheelchair propulsion: Part 1. A kinetic analysis. J Spinal Cord Med. 2005;28(3):214-21. [PMID: 16048139]

9. Kotajarvi BR, Sabick MB, An KN, Zhao KD, Kaufman $\mathrm{KR}$, Basford JR. The effect of seat position on wheelchair propulsion biomechanics. J Rehabil Res Dev. 2004;41(3B): 403-14. [PMID: 15543458]

DOI:10.1682/JRRD.2003.01.0008

10. Collinger JL, Boninger ML, Koontz AM, Price R, Sisto SA, Tolerico ML, Cooper RA. Shoulder biomechanics during the push phase of wheelchair propulsion: A multisite study of persons wi th paraplegia. Arch Phys Med Rehabil. 2008;89(4):667-76. [PMID: 18373997]

DOI:10.1016/j.apmr.2007.09.052

11. Hurd WJ, Morrow MM, Kaufman KR, An KN. Wheelchair propulsion demands during outdoor community ambulation. J Electromyogr Kinesiol. 2009;19(5):942-47.

[PMID: 18590967] DOI:10.1016/j.jelekin.2008.05.001

12. Richter WM. The effect of seat position on manual wheelchair propulsion biomechanics: A quasi-static model-based approach. Med Eng Phys. 2001;23(10):707-12.
[PMID: 11801412]

DOI:10.1016/S1350-4533(01)00074-1

13. Cowan RE, Boninger M L, Sawatzky BJ, Mazoyer BD, Cooper RA. Prelim inary outcomes of the SmartWhee 1 Users' Group database: A p roposed framework for clinicians to objectively evaluate manual wheelchair propulsion. Arch Phys Med Rehabil. 2008;89(2):260-68.

[PMID: 18226649]

DOI:10.1016/j.apmr.2007.08.141

14. Koontz AM, Yang Y, Price R, Tolerico ML, DiGiovine CP, Sisto SA, Cooper RA, Boninger ML. Multisite comparison of wheelchair propulsion kinetics in persons with paraplegia. J Rehabil Res Dev. 2007;44(3):449-58. [PMID: 18247241] DOI:10.1682/JRRD.2006.05.0048

15. Price R, Ashwell ZR, Chang MW, Boninger ML, Koontz AM, Sisto SA. Upper-limb joint power and its distribution in spinal cord injured wheelchair users: Steady-state selfselected versus maximal acceleration trials. Arch Phys Med Rehabil. 2007;88(4):456-63. [PMID: 17398246]

DOI:10.1016/j.apmr.2007.01.016

16. Fay BT, Boninger ML, Fitzgerald SG, Souza AL, Cooper RA, Koontz AM. Manual wheelchair pushrim dynamics in people with multiple sclerosis. Arch Ph ys Med Rehab il. 2004;85(6):935-42. [PMID: 15179647]

DOI:10.1016/j.apmr.2003.08.093

17. Boninger ML, Souza AL, Coop er RA, Fitzgerald SG, Koontz AM, Fay BT. Propulsion patterns and pushrim biomechanics in manual wheelchai $\mathrm{r}$ propulsion. Arch $\mathrm{Ph}$ ys Med Rehabil. 2002;83(5):718-23. [PMID: 11994814] DOI:10.1053/apmr.2002.32455

18. Cooper RA, DiGiovine CP, Boninger ML, Shimada SD, Koontz AM, Bald win MA. Filter frequency selection for manual wheelchair biomechanics. J Rehabil Res Dev. 2002; 39(3):323-36. [PMID: 12173753]

19. Cooper RA. A systems approach to the modeling of racing wheelchair propulsion. J Rehabil Res Dev. 1990;27(2): 151-62. [PMID: 2366199]

DOI:10.1682/JRRD.1990.04.0151

20. DiGiovine CP, Cooper RA, Boninger ML. Dynamic calibration of a wheelchair dynamometer. J Rehabil Res Dev. 2001;38(1):41-55. [PMID: 11322470]

21. Mercer JL, Boninger M, Koontz A, Ren D, Dyson-Hudson T, Cooper R. Shoulder joint kinetics and pathology in manual wheelchair users. Clin Biomech (Bristol, Avon). 2006;21(8): 781-89. [PMID: 16808992] DOI:10.1016/j.clinbiomech.2006.04.010

Submitted for publication October 2, 2008. Accepted in revised form May 27, 2009. 